\title{
Absence of Complement-Mediated Events after Protamine Reversal of Heparin Anticoagulation
}

\author{
Thomas W. Wakefield, M.D., ${ }^{1}$ Marvin M. Kirsh, M.D., Gerd O. Till, M.D., Thomas E. Brothers, M.D., \\ Charles B. Hantler, M.D., and James C. Stanley, M.D.
}

Sections of Vascular Surgery and Thoracic Surgery, Department of Surgery, Department of Pathology, and

Department of Anesthesiology, University of Michigan Medical Center, Ann Arbor, Michigan 48109

Submitted for publication April 26, 1990

\begin{abstract}
Protamine reversal of heparin anticoagulation is associated with adverse hemodynamic effects that may be attenuated with protamine pretreatment (PP). This study assesses the role of complement activation during these phenomena in adult cardiac surgery patients. Sixteen individuals undergoing cardiopulmonary bypass were given intravenous normal saline or protamine $(2 \mathrm{mg} / \mathrm{kg})$ as a randomized pretreatment prior to undergoing heparin anticoagulation (400 IU/kg), coronary artery revascularization, and subsequent reversal of the anticoagulated state with protamine $(4 \mathrm{mg} /$ $\mathbf{k g}$ ). Blood pressure, pulmonary artery diastolic pressure (PAD), heart rate, and cardiac output $(C O)$ were measured during and after pretreatment, prior to heparin reversal by protamine, and for $10 \mathrm{~min}$ after reversal. Total hemolytic complement (CH50), C3 conversion to C3b, C3a/C5a, platelet count, and white blood cell count (WBC) were also measured at the same time periods. No significant correlation existed between complement activation and hemodynamic events, as might have been evident by decreased CH50, increased $\mathrm{C3}$ conversion to $\mathrm{CBb}$, or elevations in $\mathrm{C3a} / \mathrm{C5a}$ levels. PP significantly prevented the CO decrease occurring at 1 and 3 min following heparin reversal by protamine ( -0.8 and -1.4 liters/min vs 0.1 and -0.2 liters $/ \mathrm{min}, P$ $<0.05$ and $P<0.01$, respectively). Reversal hypotension was less with PP, although PAD fell equally in both groups. WBC decreases after heparin reversal were less after PP $(-25 \%$ vs $-7 \%, P=0.06)$. These data support the conclusion that, contrary to earlier reports, adverse hemodynamic and hematologic responses accompanying protamine reversal of heparin anticoagulation do not appear to be correlated with activation of complement. In fact, those patients having the greatest C3a generation exhibited the least hemodynamic changes. (c) 1991 Academic Press, Inc.
\end{abstract}

\footnotetext{
1 To whom reprint requests should be addressed at University Hospital, 2210 THCC, 1500 East Medical Center Drive, Ann Arbor, MI 48109-0329.
}

\section{INTRODUCTION}

Protamine sulfate, when used to reverse the anticoagulant effects of sodium heparin during cardiac and peripheral vascular surgery, may result in undesirable hemodynamic and hematologic side effects including hypotension, bradycardia, declines in cardiac output, pulmonary artery hypertension as well as hypotension, thrombocytopenia and neutropenia [1-7]. In a prospective study of 48 adults exposed to protamine sulfate during cardiopulmonary bypass, $4 \%$ exhibited sudden increases in airway pressure, acute pulmonary hypertension, and systemic hypotension [8]. Although catastrophic events are uncommon, observable declines in blood pressure and cardiac output are common and form the basis for this study. Complement activation has been considered by other investigators to be a contributory cause to these responses [9-16]. In both dog and preliminary human studies from our center, we were not able to relate complement activation to adverse hemodynamic or hematologic events [1-3,17]. The present investigation was designed to more precisely define the role of complement activation during protamine reversal of heparin anticoagulation in patients undergoing cardiopulmonary bypass procedures with and without protamine pretreatment.

\section{METHODS}

Sixteen patients, 13 males and 3 females, ranging in age from 42 to 71 years $(\bar{x} 61)$ were studied. Patients received either pretreatment with normal saline (Group I) or protamine sulfate, $2 \mathrm{mg} / \mathrm{kg}$ (PP, Group II), as a 4-min intravenous infusion. Assignment to one or the other of these groups was done in a random, blinded manner. Five minutes following the former pretreatment, patients were anticoagulated with intravenous sodium heparin, $400 \mathrm{IU} / \mathrm{kg}$. An activated clotting time (ACT) was determined $3 \mathrm{~min}$ later, and once the ACT 
TABLE 1

Complement Activity in Group I Cardiopulmonary Bypass Patients: Saline Pretreatment prior to Heparin-Anticoagulation

\begin{tabular}{lcccc}
\hline & $\mathrm{CH} 50^{*}$ & $\begin{array}{c}\mathrm{C} 3 \text { conversion } \dagger \\
(\%)\end{array}$ & $\begin{array}{c}\mathrm{C} 3 \mathrm{a}^{* *} \\
(\mu \mathrm{g} / \mathrm{ml})\end{array}$ & $\begin{array}{c}\mathrm{C} 5 \mathrm{a} \ddagger \\
(\mathrm{ng} / \mathrm{ml})\end{array}$ \\
\hline $\begin{array}{l}\text { Prior to protamine } \\
\text { administration }\end{array}$ & 54 & 21.2 & 4.1 & 14.8 \\
$3 \begin{array}{l}\text { min following } \\
\text { completion of } \\
\text { protamine } \\
\text { administration }\end{array}$ & 63 & 21.6 & 4.6 & 15.9 \\
\hline
\end{tabular}

Note. Statistical analyses (paired $t$ tests) comparing complement before and following protamine administration: ${ }^{*}$ no activation, $\uparrow P$ $=0.90,{ }^{* *} P=0.52, \ddagger P=0.30$.

was documented to be $>400 \mathrm{sec}$, patients were placed on cardiopulmonary bypass and underwent coronary revascularization.

The cardiopulmonary bypass circuit oxygenator consisted of a Sci-Med (Sci-Med, Minneapolis, MN) or a Maxima (Medtronics, Minneapolis, MN) device. Oxygenator priming solutions and cardioplegia solutions were the same in all patients. Mean cross-clamping time was $42 \pm 10 \mathrm{~min}$ with no differences between the groups (44 and 40 min in Groups I and II, respectively), while mean pump time was $81 \pm 28$ min with again no differences between groups ( 80 and $82 \mathrm{~min}$ in Groups I and II, respectively). At the conclusion of the arterial reconstruction, the anticoagulated state was reversed with in travenous protamine, $4 \mathrm{mg} / \mathrm{kg}$, infused over $8 \mathrm{~min}$. All patients gave informed consent according to an approved University of Michigan Human Use Committee protocol.

Associated diseases in study patients, including chronic obstructive pulmonary disease, previous myocardial infarction, systemic arterial hypertension, and diabetes mellitus did not vary among the two pretreatment groups. The preoperative ejection fraction averaged greater than $50 \%$ in 12 patients, was unknown in 4 patients, and was not significantly different between the two pretreatment groups. Coronary reconstruction involved at least two saphenous vein bypass grafts in all patients, and additional internal mammary artery bypasses were performed in 10 patients.

Hemodynamic parameters measured during the study included mean systemic arterial blood pressure (BP) by way of an indwelling radial artery line; pulmonary artery diastolic pressure (PAD) by way of a Swan-Ganz catheter placed into the pulmonary artery; central venous pressure by way of a catheter placed into the internal jugular vein; heart rate from the arterial line tracing; and cardiac output $(\mathrm{CO})$ measured by thermodilution technique. Measurements were made during and after saline or protamine pretreatment, just prior to protamine reversal of heparin anticoagulation at the conclusion of cardiopulmonary bypass, and for $10 \mathrm{~min}$ following protamine reversal. Platelet counts and white blood cell counts were measured prior to pretreatment, after pretreatment, after heparin administration, prior to protamine reversal, and at 1,3 , and $10 \mathrm{~min}$ following protamine reversal of heparin anticoagulation.

Total hemolytic complement ( $\mathrm{CH} 50)$ and $\mathrm{C} 3$ conversion to $\mathrm{C} 3 \mathrm{~b}$ were measured prior to pretreatment, prior to protamine reversal, and $3 \mathrm{~min}$ after protamine reversal. CH50 was defined under rigidly standardized conditions as the quantity of complement necessary for $50 \%$ lysis of sheep red blood cells sensitized with rabbit antisheep red blood cell antibody. Conversion of C3 to C3b was assayed using crossed immunoelectrophoresis. The amount of $\mathrm{C} 3$ conversion was determined on the basis of the relative electrophoretic mobility of $\mathrm{C} 3$ and C3b. C3a and C5a plasma levels were measured prior to protamine reversal and $3 \mathrm{~min}$ after the conclusion of protamine administration using conventional radioimmunoassay techniques for C3a des Arg and C5a des Arg, respectively (Amersham, Arlington Heights, IL). Statistical evaluation of the data included use of paired and unpaired Student's $t$ tests and linear correlations where appropriate. Statistical significance was defined at $P \leqslant 0.05$.

\section{RESULTS}

Evidence of complement activation occurring as a consequence of protamine reversal of heparin anticoagulation was not forthcoming from data generated in this study (Tables 1 and 2). An increase in C3 conversion to C3b, from $13.4 \pm 20.0$ to $21.2 \pm 9.0 \%$ in Group I, and

\section{TABLE 2}

Complement Activity in Group II Cardiopulmonary Bypass Patients: Protamine Pretreatment prior to Heparin Anticoagulation

\begin{tabular}{lcccc}
\hline & $\mathrm{CH} 50^{*}$ & $\begin{array}{c}\mathrm{C} 3 \text { conversion } \dagger \\
(\%)\end{array}$ & $\begin{array}{c}\mathrm{C} 3 \mathrm{a}^{* *} \\
(\mu \mathrm{g} / \mathrm{ml})\end{array}$ & $\begin{array}{c}\mathrm{C} 5 \mathrm{a} \ddagger \\
(\mathrm{ng} / \mathrm{ml})\end{array}$ \\
\hline $\begin{array}{l}\text { Prior to protamine } \\
\text { administration }\end{array}$ & 43 & 20.5 & 3.2 & 10.3 \\
$\begin{array}{l}3 \text { min following } \\
\text { completion of } \\
\text { protamine }\end{array}$ & & & & \\
$\quad$ administration & 70 & 24.0 & 7.7 & 13.8 \\
\hline
\end{tabular}

Note. Statistical analyses (paired $t$ tests) comparing complement before and following protamine administration: ${ }^{*}$ no activation, $\dagger P$ $=0.23,{ }^{* *} P=0.02, \ddagger P=0.20$. 
from $13.6 \pm 20.0$ to $20.5 \pm 12.0 \%$ in Group II, occurred between baseline and just prior to protamine reversal. However, little activation was noted during actual protamine exposure. In Group I, C3 conversion increased almost imperceptibly from $21.2 \pm 9.0$ to $21.6 \pm 9.0 \%$ after reversal, and in Group II a similarly insignificant increase occurred from $20.5 \pm 12.0$ to $24.0 \pm 18.5 \%$. Diminished total hemolytic complement, indicating complement activation, occurred between baseline and just prior to protamine reversal, with decreases of $135 \pm 64$ to $54 \pm 28 \mathrm{CH} 50$ units noted in Group I, and decreases of $112 \pm 17$ to $43 \pm 26 \mathrm{CH} 50$ units occurring in Group II. No complement activation occurred following protamine reversal in Group I patients, with an increase of CH50 from $54 \pm 28$ to $63 \pm 39$ units being noted, or in Group II patients, with an increase in CH50 from $43 \pm 26$ to 70 \pm 39 CH50 units being evident.

No correlations between obvious hemodynamic events and complement activity existed in this study. No significant correlation occurred between changes in CH50 and changes in BP in either treatment group after protamine reversal $(P \geqslant 0.09)$. Similarly, no significant correlation existed between changes in $\mathrm{CH} 50$ and changes in CO in either treatment group at 1,3 , or 10 min following protamine reversal $(P \geqslant 0.31)$. Finally, no significant correlation occurred between changes in CH50 and changes in PAD in either treatment group ( $P$ $>0.05$ ).

A lack of significant correlation was also observed when $\mathrm{C} 3$ conversion to $\mathrm{C} 3 \mathrm{~b}$ was compared to changes in $\mathrm{CO}$ in either treatment group $(P \geqslant 0.20)$. Isolated significant correlations were noted between declines in BP in Group II patients and elevations in C3 conversion to C3b 10 min after reversal $(P=0.02)$ and between declines in PAD in Group II patients and elevations in C3 conversion to $\mathrm{C} 3 \mathrm{~b} 3$ and $4 \mathrm{~min}$ after reversal $(P<0.05)$.

C3a levels increased after protamine reversal from 4.1 \pm 2.2 to $4.6 \pm 1.8 \mu \mathrm{g} / \mathrm{ml}$ in Group I patients, and from 3.2 \pm 1.2 to $7.7 \pm 5.0 \mu \mathrm{g} / \mathrm{ml}$ in Group II subjects. No significant correlations existed between $\mathrm{C} 3 \mathrm{a}$ increases during protamine reversal and changes in $\mathrm{BP}(P \geqslant 0.06), \mathrm{CO}(P$ $\geqslant 0.05)$, or PAD $(P \geqslant 0.07)$. The highest generation of C3a was a $131 \%$ increase noted in Group II protamine pretreated patients $(P<0.05)$. A small increase in C5a levels occurred from $14.8 \pm 3.4$ to $15.9 \pm 2.2 \mathrm{ng} / \mathrm{ml}$ in Group I and $10.3 \pm 4.2$ to $13.8 \pm 4.0 \mathrm{ng} / \mathrm{ml}$ in Group II. No significant correlations existed between C5a elevations and changes in $\mathrm{CO}(P \geqslant 0.20)$ or PAD $(P \geqslant 0.07)$. The only significant correlation between C5a elevations and $\mathrm{BP}$ changes occurred at $11 \mathrm{~min}$ after protamine reversal in Group II where C5a elevation was related to BP decline $(P<0.05)$.

Protamine pretreatment did prevent the fall in $\mathrm{CO}$ that occurred 1 and 3 min following heparin reversal by

\section{TABLE 3}

Cardiac Output Change in Cardiopulmonary Bypass Patients following Protamine Reversal of Heparin Anticoagulation

\begin{tabular}{lccc}
\hline & $\begin{array}{c}\text { Saline } \\
\text { pretreatment, } \\
\text { Group I } \\
\text { (liters/min) }\end{array}$ & $\begin{array}{c}\text { Protamine } \\
\text { pretreatment } \\
\text { Group II } \\
\text { (liters/min) }\end{array}$ & \\
\hline 1 min following \\
$\begin{array}{l}\text { completion of protamine } \\
\text { administration } \\
3 \text { min following } \\
\text { completion of protamine } \\
\text { administration }\end{array}$ & -0.8 & 0.1 & $P<0.05$ \\
$\begin{array}{l}10 \text { min following } \\
\text { completion of protamine } \\
\text { administration }\end{array}$ & -1.4 & -0.2 & $P<0.01$ \\
\hline
\end{tabular}

protamine $(-0.8$ and -1.4 liters $/ \mathrm{min}$ vs 0.1 and -0.2 liters $/ \min P<0.05, P<0.01$, respectively, Table 3 ). Protamine pretreatment diminished hypotension following protamine reversal, with the maximal mean drop in BP in Group I patients being $-12 \mathrm{~mm} \mathrm{Hg}$ vs $-6 \mathrm{~mm} \mathrm{Hg}$ in Group II patients, although these differences were not statistically different. There were no group differences in PAD changes. Similarly, no group differences occurred in the magnitude of thrombocytopenia, although there was a difference in the degree of leukopenia, with Group I and Group II changes being $-25 \pm 7$ and -7 $\pm 22 \%$, respectively $(P=0.06)$. The degree of thrombocytopenia occurring during pretreatment appeared related to the drop in blood pressure observed at the conclusion of protamine reversal $\left(r^{2}=0.55, P<0.05\right), 5 \mathrm{~min}$ after the conclusion of reversal $\left(r^{2}=0.68, P<0.05\right)$, as well as $7 \mathrm{~min}$ after the conclusion of reversal $\left(r^{2}=0.62\right.$, $P<0.05)$.

Comparable numbers of Group I and II patients, ( $n$ $=6$ and $n=7$, respectively) required small amounts of additional heparin during cardiopulmonary bypass to maintain an activated clotting time of at least $400 \mathrm{sec}$. The total heparin dose per individual in Group I patients $(35,000 \pm 8,000 \mathrm{IU})$ was less than the heparin dose in Group II patients $(48,125 \pm 14,147 \mathrm{IU}, P<0.05)$. At the conclusion of protamine reversal, similar numbers of Group I and II patients ( $n=4$ and $n=3$, respectively) required additional protamine sulfate to reverse their heparin anticoagulation.

\section{DISCUSSION}

Complement activation has been purported to cause the adverse hemodynamic and hematologic side effects 
accompanying protamine sulfate reversal of heparin anticoagulation. Early in vitro studies suggested that heparin and protamine combinations, at levels below those causing complement activation by either substance alone, depleted total hemolytic complement in the fashion of an antibody-antigen complex through the classical pathway of complement activation $[10,11]$. These studies were followed by in vivo rabbit studies in which generation of C5a was implicated by the existence of a transient granulocytopenia produced by heparin-protamine interactions [12]. Clinical investigations followed these former studies.

In 100 cardiopulmonary bypass patients treated at the Mayo Clinic, C3a and C4a levels were measured at regular intervals before and after administering protamine $(1.3 \mathrm{mg} / 100 \mathrm{IU}$ heparin) over a 5 - to 10 -min interval [13]. The protamine dosage in this Mayo Clinic study is approximately $10 \%$ greater than that in the present study. In this study, 90 patients received protamine 5 min after the conclusion of the cardiopulmonary bypass, and 10 patients received protamine at the time of skin closure approximately $45 \mathrm{~min}$ after discontinuing the cardiopulmonary bypass. C4a was not activated during cardiopulmonary bypass in either group. However, C4a increased some twofold $10 \mathrm{~min}$ after protamine administration $5 \mathrm{~min}$ following bypass. C4a level did not increase with the delayed administration of protamine. Since C4a generation dues not involve activation of complement by way of the alternate pathway, protamine most likely effected classical complement pathway activation. C3a activation was also documented in this study. The authors concluded that complement activation, pulmonary sequestration of leukocytes, lysosome enzyme release, superoxide generation, histamine release from mast cells, and increased capillary permeability occurred in response to protamine reversal of heparin. Two facts about this study make it difficult to extrapolate its data to those of the present investigation. First, patients in the Mayo study did not exhibit reversal hypotension and thus correlations between hemodynamic changes and complement activation were not possible. Second, the measurements in the Mayo study were obtained a full 10 min following protamine reversal, a time beyond that when adverse responses have been known to occur.

A study similar to that from the Mayo Clinic was undertaken by Kirklin and his colleagues at the University of Alabama. In the latter investigation, 20 patients were given a mean protamine dose of $\mathbf{4 1 0} \mathrm{mg}$ (approximately $20 \%$ greater than the present study) over $5 \mathrm{~min}$ after cardiopulmonary bypass [14]. Peak levels of C3a and C4a occurred 10 min after the start of protamine administration or $5 \mathrm{~min}$ after its completion. Thereafter, C3a levels fell steadily and were near normal at $24 \mathrm{hr}$. In the case of $\mathrm{C} 4 \mathrm{~d}$, the peak $\mathrm{C} 4 \mathrm{~d}-\mathrm{C} 4$ ratio occurred 5 min after protamine administration, and remained elevated for 48 hr. No change in C5a was noted with protamine administration. A drop in white blood cell count from 9150 to 6770 occurred in this study $1 \mathrm{~min}$ before to $5 \mathrm{~min}$ after protamine administration, and a fall in platelet count from 107,930 to 76,550 occurred during the same time interval. No patient in this study demonstrated an important adverse hemodynamic reaction to protamine.

In contrast to the two former clinical studies, a third report in humans undergoing cardiopulmonary bypass revealed no consumption of complement, particularly $\mathrm{C} 3$ and C4 [16]. However, in this latter study C3a and $\mathrm{C} 4 \mathrm{a}$ levels were not quantitated, but instead total $\mathrm{C} 3$ and $\mathrm{C} 4$ was measured by radioimmunodiffusion. Such an assay may not be sensitive enough to demonstrate complement activation.

We have assessed the relevance of complement activation by protamine in three previous investigations, including two canine studies and one human study involving patients undergoing abdominal aortic replacement $[2,3,17]$. We were unable to demonstrate any correlation between hemodynamic changes and C3a generation or changes in total hemolytic complement. In one of the former canine studies, eight animals were depleted of complement by intraperitoneal administration of Naja n. naja cobra venom factor, 20 units $/ \mathrm{kg}, 48$ and $24 \mathrm{hr}$ ( 40 units/kg total dose) prior to anticoagulation with heparin and subsequent reversal with protamine [17]. Despite confirmed decomplementation, the maximal hemodynamic changes in these animals were similar to those occurring in animals who were not complement depleted, including a BP decrease of $-43 \mathrm{~mm} \mathrm{Hg}$, a heart rate decrease of -16 , a PAD increase of $+3 \mathrm{~mm} \mathrm{Hg}$, a CO decline of $-27 \%$, and platelet and white blood cell count declines of $-49 \%$ and $-48 \%$, respectively. This study supports the conclusions that complement components $\mathrm{C} 3$ and $\mathrm{C} 5$ to $\mathrm{C} 9$ are not influential factors in causing protamine-heparin induced hemodynamic changes and that classical pathway activation is not a major factor contributing to these adverse responses.

No relation was established in the present study between total hemolytic complement, C3 conversion to C3b by crossed immunoelectrophoresis, or C3a/C5a anaphylatoxin levels and changes in BP, CO, or PAD. In fact, patients with the least fall in CO, those in Group II receiving protamine pretreatment, showed the highest plasma levels of C3a. Thus, complement activation in animals and humans following protamine administration does not appear to be a primary cause of the hemodynamic and hematologic changes accompaning administration of this drug.

C3 conversion (assessed by crossed immunoelectrophoresis) during cardiopulmonary bypass is well known 
and has been reported to be $6.4 \%$ [18], a value similar to the $7.8 \%$ observed in the present study in Group I. Likewise, complement activation during cardiopulmonary bypass, as measured by a fall in CH50, is well accepted and has been reported to be $25 \%$ [19], which is lower than the $60 \%$ encountered in our series in Group I. Regarding C3a levels, we noted a little over a onefold increase in the Group I saline pretreatment group and an approximate twofold increase in the Group II protamine pretreated patients after reversal. In the Mayo Clinic study, there also was an approximate twofold increase in $\mathrm{C} 3 a$ levels measured prior to and after protamine reversal in the 90 patients who received protamine at the usual time after cardiopulmonary bypass, and in those receiving delayed administration of protamine, there was approximately a $50 \%$ increase [13]. The Alabama study documented a threefold increase in C3a after protamine administration, but no significant generation of C5a. This was similar to our study where C5 activation was also much less than $\mathrm{C} 3$ activation with at most a $7 \%$ elevation of C5a noted in Group I and a 34\% elevation of C5a noted in Group II patients. Thus, the magnitude of changes in all complement parameters measured in the present investigation were similar to those in previous reports.

The principal difference between our study and earlier studies by others is the correlations drawn between complement activation and hemodynamic side effects. In fact, we found no significant correlations between complement activation and adverse hemodynamic side effects. The present study strongly suggests that complement activation from protamine-heparin interaction is not a primary factor in the production of adverse hemodynamic and hematologic changes associated with protamine reversal of heparin anticoagulation. Although complement activation may occur in these patients, it does not appear to have a direct causal relation to the adverse reactions accompanying protamine administration.

\section{REFERENCES}

1. Wakefield, 'I'. W., Whitehouse, WM., Jr., and Stanley, J. C. Depressed cardiovascular function and altered platelet kinetics following protamine sulfate reversal of heparin activity. J. Vasc. Surg. 1: 346, 1984.

2. Wakefield, T. W., Hantler, C. B., Lindblad, B., Whitehouse, WM., Jr., and Stanley, J. C. Protamine pretreatment attenuation of hemodynamic and hematologic effects of heparin-protamine interaction: A prospective randomized study in human beings undergoing aortic reconstructive surgery. J. Vasc. Surg. 3: $885,1986$.

3. Wakefield, T. W., Lindblad, B., Whitehouse, WM., Jr., Hantler, C. B., and Stanley, J. C. Attenuation of hemodynamic and hematologic effects of heparin-protamine sulfate interaction after aortic reconstruction in a canine model. Surgery 100: 45, 1986.

4. Wakefield, T. W., Bouffard, J. A., Spaulding, S. A., Petry, N. A.,
Gross, M. D., Lindblad, B., and Stanley, J. C. Sequestration of platelets in the pulmonary circulation as a consequence of protamine reversal of the anticoagulant effects of heparin. $J$. Vasc. Surg. 5: 187, 1987.

5. Horrow, J. C. Protamine: A review of its toxicity. Anesth. Analg. 64: $348,1985$.

6. Jacques, L. B. A study of the toxicity of the protamine, salmine. Brit. J. Pharmacol. 4: 135, 1949.

7. Gupta, S. K., Veith, F. J., Ascer, E., Wengerter, K. R., Franco, C., Amar, D., El-Gaweet, E-S., and Gupta, A. Anaphylactoid reactions to protamine: An often lethal complication in insulin-dependent diabetic patients undergoing vascular surgery. $J$. Vasc. Surg. 9: 342, 1989.

8. Morel, D. R., Zapol, W. M., Thomas, S. T., Kitain, E. M., Robinson, D. R., Moss, J., Chenoweth, D. E., and Lowenstein, E. C5a and thromboxane generation associated with pulmonary vasoand broncho-constriction during protamine reversal of heparin. Anesthesiology 66: 597, 1987.

9. Kirklin, J. K. In discussion of: Shapiro, N., Schaff, H. V., Piehler, J. M., White, R. D., Sill, J. C., and Pluth, J. R. Cardiovascular effects of protamine sulfate in man. J. Thorac. Cardiovasc. Surg. 84: 505, 1982.

10. Siegel, J., Rent, R., and Gewurz, H. Interactions of C-reactive protein with the complement system. I. Protamine-induced consumption of complement in acute phase sera. J. Exp. Med. 140: 631, 1974.

11. Rent, R., Ertel, N., Eisenstein, R., and Gewurz, H. Complement activation by interaction of polyanions and polycations. I. Heparin-protamine induced consumption of complement. $J$. Immunol. 114: 120, 1975.

12. Fehr, J., and Rohr, H. In vivo complement activation of polyanion-polycation complexes: Evidence that C5a is generated intravascularly during heparin-protamine interaction. Clin. Immunol. Immunopathol. 29: 7, 1983.

13. Cavarocchi, N. C., Schaff, H. V., Orszulak, T. A., Homberger, H. A., Schnell, W. A., and Pluth, J. R. Evidence for complement activation by protamine-heparin interaction after cardiopulmonary bypass. Surgery 98: 525, 1985.

14. Kirklin, J. K., Chenoweth, D. E., Naftel, D. C., Blackstone, E. H., Kirklin, J. W., Bitran, D. A., Curd, J. G., Reves, J. G., and Samuelson, P.N. Effects of protamine administration after cardiopulmonary bypass on complement, blood elements and the hemodynamic state. Ann. Thorac. Surg. 41: 193, 1986.

15. Best, N., Sinosich, M. J., Teisner, B., Brudzinskas, J. G., and Fisher, M. M. Complement activation during cardiopulmonary bypass by heparin-protamine interaction. Brit. J. Anaesth. 56: $339,1984$.

16. Chiu, R. C. J., and Samson, R. Complement (C3, C4) consumption in cardiopulmonary bypass, cardioplegia, and protamine administration. Ann. Thorac. Surg. 37: 229, 1984.

17. Wakefield, T. W., Till, G. O., Lindblad, B., Saenz, N., and Stanley, J. C. Complement depletion and hemodynamic-hematologic responses in protamine-heparin reactions. J. Surg. Res. 45: 320 , 1988.

18. Bascoe, M. J., Yewdall, V. M., Thompson, M. A., and Cameron, J. S. Complement activation during cardiopulmonary bypass: Quantitative study of effects of methylprednisolone and pulsatile flow. Brit. Med. J. 287: 1747, 1983.

19. Hammerschmidt, D. E., Stroncek, D. F., Bowers, T. K., LammiKeefe, C. J., Kurth, D. M., Ozalins, A., Nicoloff, D. M., Lillehei, R. C., Craddock, P. R., and Jacob, H. S. Complement activation and neutropenia occurring during cardiopulmonary bypass. $J$. Thorac. Cardiovasc. Surg. 81: 370, 1981. 